\title{
Global observations of ROTI by using ground-based GNSS receivers
}

\author{
Jann-Yenq Liu ${ }^{1,2,3, *}$ and Shih-An $\mathrm{Wu}^{2}$ \\ ${ }^{1}$ Center for Astronautical Physics and Engineering, National Central University, Taoyuan City, Taiwan \\ ${ }^{2}$ Department of Space Science and Engineer, National Central University, Taoyuan City, Taiwan \\ ${ }^{3}$ Center for Space and Remote Sensing Research, National Central University, Taoyuan City, Taiwan
}

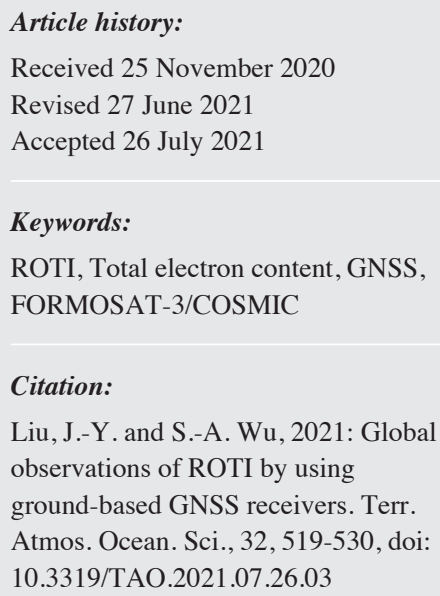

Citation:

Liu, J.-Y. and S.-A. Wu, 2021: Global observations of ROTI by using ground-based GNSS receivers. Terr. Atmos. Ocean. Sci., 32, 519-530, doi: 10.3319/TAO.2021.07.26.03

\begin{abstract}
Diurnal, monthly, and solar activity variations in L-band signal fluctuations are examined by ROTI (Rate Of Tec Index) derived from measurements of worldwide ground-based GNSS (Global Navigation Satellite System) receivers in 2000, 2009, and 2013. Routine observations of the ionospherically imposed propagation effects upon GNSS satellite signals are available online from IGS (International GNSS Service). With data over 2000 ground-based IGS stations of the globe, ionospheric TEC with the 30-sec time resolution can be derived. The standard deviation of TEC variations every minute in a 5-minute interval is further computed to obtain ROTI around each receiving station. Variations in diurnal, seasonal, solar activity, and geographic distribution of ROTI are examined during the solar maximum year of 2000, solar minimum year of 2009, and solar median year of 2013. ROTIs are proportional to the solar activity, those in the high-latitude ionosphere are much more intense than in the low- and mid-latitude ionosphere. In the low-latitude ionosphere, intense ROTIs frequently occur within $\pm 30^{\circ}$ magnetic dip, start at 19:30 LT (Local Time); reach their maximum at 20:00 to 21:00 LT, and vanish by about 02:00 LT; and appear prominently in March and September equinox seasons. The region experiencing the most intense ROTI is the low-latitude ionosphere in South America. The low-latitude ROTIs often exhibit a prominent double-peaked (or crest) structure centering at $20^{\circ} \mathrm{N}$ and $20^{\circ} \mathrm{S}$ dip latitude, especially in high/median solar activity years of 2000 and 2013. Monthly-longitude plots of low latitude ROTIs look like a masquerade mask with two eye holes (i.e., ROTI free).
\end{abstract}

\section{INTRODUCTION}

Plasma instability phenomena (or irregularities) occurring in the F-region ionosphere are usually grouped under the generic name spread F. This stems from the earliest observations using HF (high frequency) ionosondes, which showed that on occasion the reflected echo did not display a well-behaved pattern but was "spread" in range or frequency (Berkner and Wells 1934). Range and frequency spreads tend to occur in the equatorial latitude and high latitude F-region, respectively. Undoubtedly, spread F can be caused by the scattering of the signal from plasma irregularities embedded in the ionosphere. Plasma irregularities are important in HF and VHF (very high frequency) radio propagations because the time spreading limits the rate of

\footnotetext{
* Corresponding author

E-mail: tigerjyliu@gmail.com
}

information transfer and because it produces high fading rates (Davies 1990). Several rockets and satellites have penetrated both irregularity layers and the plume structures. For such studies, it has proven being useful to correlate the in situ probing with scanning ground-based radars and sounding rockets (cf. Kelley 2009).

Liu et al. (2016) study S4 scintillation index profiles of GPS L-band signals by using the radio occultation (RO) technique of the FORMOSAT-3/COSMIC (F3/C) satellites, and compare the global F3/C S4 observations with geostationary satellite VHF signals observed on the ground (Basu et al. 1988), ion density irregularities probed by the ROCSAT-1 satellite (Su et al. 2006), and co-located S4-index recorded by ground-based GNSS (global navigation satellite system) receivers. They find that diurnal variations of prominent F3/C S4 scintillations occurring at the magnetic 
equator and low-latitude ionosphere in the postsunset-postmidnight period, nightside auroral oval, dayside cusp, and 24-hr polar cap generally agree with those of VHF signals (Basu et al. 1988) the geographic distribution in various seasons of F3/C S4 scintillations is nearly identical to that of the occurrence rate for ion density irregularities of ROCSAT-1 (Su et al. 2006); and the F3/C S4-index and co-located ground-based GNSS S4-index yield similar tendencies. These similarities confirm that plasma irregularities can significantly affect the amplitude of radio waves by high fading rates or scintillations.

On the other hand, researchers employed high sample rate of $50 \mathrm{~Hz}$ GNSS signals to study amplitude and phase scintillations and losses of signal lock in the high-latitude ionosphere during severe space weather and great storms (Moen et al. 2013; Jin et al. 2014, 2017; Van der Meeren et al. 2015; Clausen et al. 2016; Wang and Morton 2017; Jin and Oksavik 2018). However, owing to the high sample rate of $50 \mathrm{~Hz}$, the spatial coverage of these studies is limited. By contrast, for the low sampling rate of 30 -sce, Pi et al. (1997) introduced ROTI [Rate Of Total electron content (TEC) Index] as a GPS-based index that characterizes the severity of the GNSS phase fluctuations, and detects the presence of ionospheric irregularities, as well as measures the irregular structures of TEC spatial gradient. Scientists have been using ROTI to observe irregularities in the highlatitude ionosphere (Krankowski et al. 2006; Jacobsen and Schäfer 2012; Jacobsen 2014; Cherniak et al. 2015, 2018; Cherniak and Zakharenkova 2016). Cherniak et al. (2018) employed measurements from about 700 ground-based GPS stations to intensively monitor ROTI located at high and middle latitudes, $50-90^{\circ} \mathrm{N}$ in geomagnetic, of the Northern hemisphere and 00 - 24 magnetic local time, while Kotulak et al. (2020) utilized two chains of GNSS stations located in European and North-American regions to examine ROTIs at high latitudes. These studies show that ROTIs in the low and middle latitudes have not yet been studied in detail.

The advantage of ROTIs is the low sampling rate of 30 -sce, which can be applied on measurements of worldwide ground-based GNSS receivers of IGS (International GNSS services). In this study, based on Pi et al. (1997), we examine ionospheric TEC derived from measurements of more than 2000 receiving stations, and report the global ROTI in various local times, seasons, locations during the solar maximum year of 2000 [Sunspot number $\mathrm{R}=174$; The solar radio flux at $10.7 \mathrm{~cm}(2800 \mathrm{MHz}) \mathrm{F} 10.7=180 \mathrm{sfu}]$, minimum year of $2009(\mathrm{R}=5 ; \mathrm{F} 10.7=71 \mathrm{fsu})$, and median year of $2013(\mathrm{R}=94 ; \mathrm{F} 10.7=123 \mathrm{fsu})$.

\section{GLOBAL ROTI OBSERVATION}

The IGS network currently consists of more than 2000 permanent receiving stations routinely recording the dual frequency L-band (1.575 and $1.227 \mathrm{GHz})$ signals transmit- ted from GNSS satellites, which can be employed to derive the slant TEC around the station every 30-sec (Liu et al. 1996). To identify and to statistically present the smaller scale irregularities, Pi et al. (1997) define ROTI based on the standard deviation of ROT (rate of slant TEC changes every minute) for each 5-minute time interval, which is given as,

ROTI $=\sqrt{\left.<\text { ROT }^{2}>-<\text { ROT }\right\rangle^{2}}$

where ROT at "i" time point is calculated by TEC $(\mathrm{i}+30$ sec) minus TEC(i $30 \mathrm{sec})$ and slide by 30 -sec. Therefore, in each 5-minute time interval, there are 10 ROTs to calculate an associated ROTI. Here, for a GPS satellite above the 30-deg elevation angle, ROTI is computed every 30 -sec. Usually, signals of 8 - 10 GPS satellites can simultaneously be recorded by a receiver, and therefore, more than 960 (= $120 \times 8$ ) ROTIs are computed every hour.

Figure 1 displays GPS satellite signals recorded by more than 2000 worldwide ground-based receiving stations of the IGS network, which can be used to derive TECs and ROTIs monitoring smaller scale ionospheric plasma irregularities and associated phase fluctuations of GPS signals. Figure 2 illustrates TEC and ROTI at a low-latitude GNSS receiving station of areq $\left(-16.02^{\circ} \mathrm{N},-71.62^{\circ} \mathrm{E},-9.16^{\circ} \mathrm{dip}\right)$ on 23 September 2013. It can be seen that TECs yield smallamplitude and high-frequency fluctuations, which result in prominent ROTIs during the postsunset of 19:20 LT-postmidnight of 02:00 LT. To have a better understanding on phase fluctuations of GPS signals in various local times, seasons, solar activities, and latitudes, global ROTI observations are further subdivided into three latitudinal zones: low (within $\left.\pm 30^{\circ}\right)$, middle $\left(30-60^{\circ}\right)$, and high $\left(60-90^{\circ}\right)$ dip-latitude (dLat) in the Northern/Southern hemispheres; as well as four seasons: M-month ( \pm 45 days to March equinox), J-month ( \pm 45 days to June solstice), S-month $( \pm 45$ days to September equinox), and D-month ( \pm 45 days to December solstice). Figure 3 displays global distributions of the median of ROTIs during 20:00 to 02:00 LT in various months of 2000, 2009, and 2013. ROTIs are intense at the high latitude, especially in the Southern hemisphere, moderate at the low latitude, and rather weak at the middle latitude. The low-latitude ROTI appears constantly in all longitudes and becomes prominent, especially Southern American, African, and Asian longitudes in M- and S-month; reaches the most intense over the South American longitude in D-month; and becomes very weak, except some scattered moderate over Africa in J-month in 2000 and 2013. In 2009, ROTIs generally are very weak, excluding moderate ones appear over the South American longitudes in M- and Smonth. ROTIs in the low and high latitude ionosphere show clear solar activity effects.

Figure 4 depicts that the low-latitude ROTI crests situate within $\pm 35^{\circ} \mathrm{dLat}$ and center at $\pm 15^{\circ} \mathrm{dLat}$, starting from 
1800 MLT (magnetic local time), reaching maximum intensity at 2100 MLT, and ending by 0200 MLT. The ROTI crest in the Southern hemisphere is more intense than that in the Northern hemisphere, while the F3/C S4 index vice versa (Liu et al. 2016; Chen et al. 2017). The appearance time (latitude) of crest peak in 2000 and 2013 are earlier (higher) than that in 2009 in each hemisphere, which displays clear solar activity signatures. These agree with Liu et al. (2016) and Chen et al. (2017) that F3/C S4 index crest peaks appear earlier and more poleward in 2013 than those in 2008 in each hemisphere. The high- (or polar-) latitude ROTIs also reveal clear solar activity effects, as well as become prominent at $\pm 60^{\circ} \mathrm{dLat}$ and develop more strongly toward the magnetic poles but yet with no obvious diurnal variations. In general, the diurnal variation patterns of ROTIs and $\mathrm{S} 4$ index are similar, except the ROTI is more prominent in the high-latitude than that in the low-latitude, while the F3/C S4 index vice versa (Liu et al. 2016; Chen et al. 2017). Monthly variations in Fig. 5 display that ROTI dur- ing 1800 to 0200 MLT becomes intense and expands over $\pm 35^{\circ} \mathrm{dLat}$ in the equinox months with relatively higher than those in the other seasons, and then decreases and shrinks down to $\pm 20^{\circ}$ in the following solstice months. Note that ROTI decreases and shrinks slowly from September to December. Generally, the intensity and latitudinal range of the low-latitude ROTI are proportional to the solar activity and reach their maximum in the equinox months of the solar maximum 2000. The low-latitude ROTI becomes rather weak in the solar minimum of 2009, especially in May to August. The monthly variations of ROTI being similar to those of S4 (Liu et al. 2016; Chen et al. 2017) are proportional to the solar activity. Although similar responses to the solar activity, ROTIs are more prominent in the high-latitude than those in the low-latitude, while S4 index vice versa.

We further examine ROTI and TEC at the low, middle, and high latitudes during various seasons and solar activities. Figure 6 depicts that in the low latitudes, ROTI and

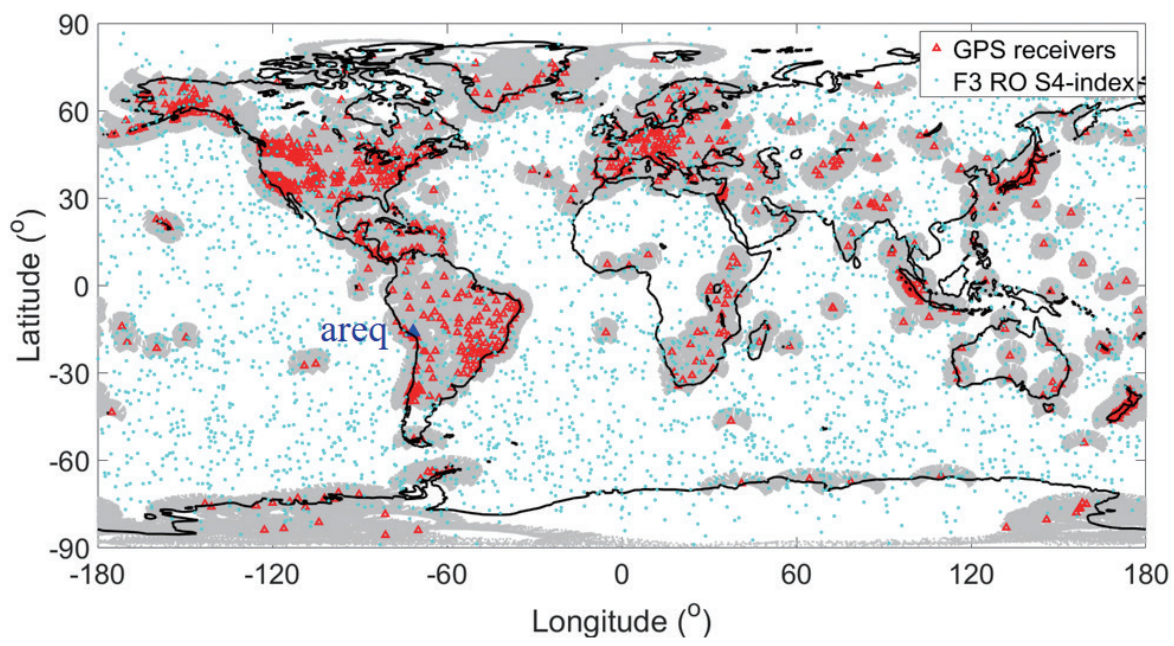

Fig. 1. The daily coverage of FORMOSAT-3 radio occultation S4 index and geographic locations of global GPS stations in the IGS network. Arequipa station is marked by blue triangle, and the others are in red. The gray area at each station denotes the field of view of a $30^{\circ}$ elevation angle. The cyan points stand for the FORMOSAT-3 radio occultation S4 index.
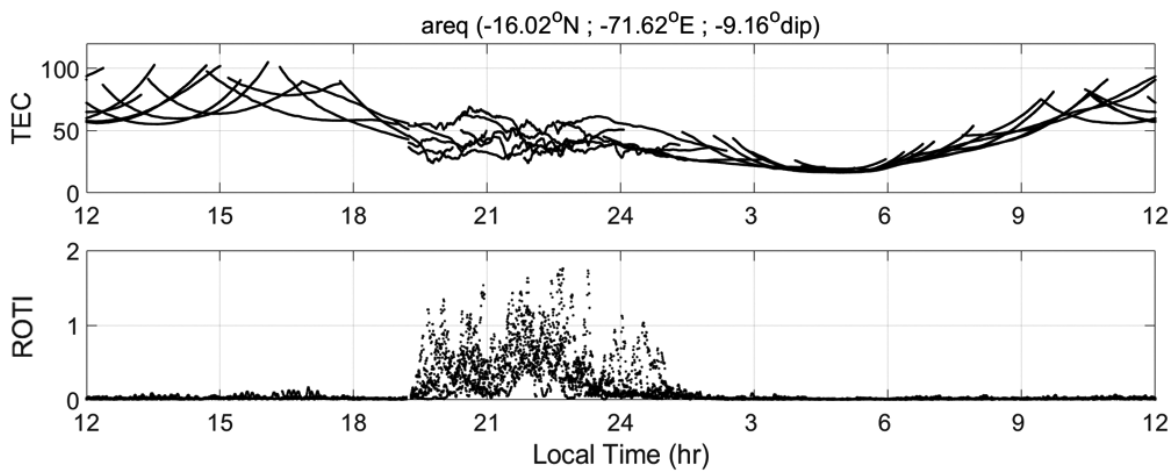

Fig. 2. TEC and ROTI recorded in Arequipa (areq) station on 23 September 2013. The time resolution of the two quantities is 30 sec. In total more than $23040(=120 \times 24 \times 8)$ data points in TEC or ROTI on the day. 


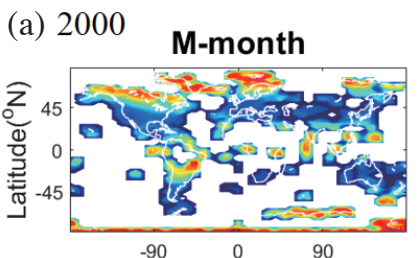

(b) 2009 M-month

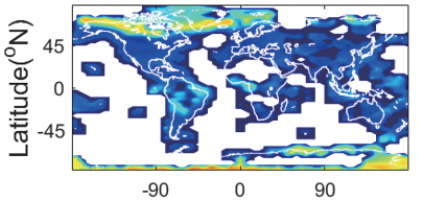

(c) 2013 M-month

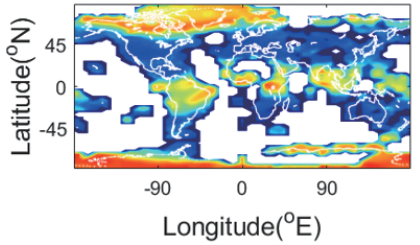

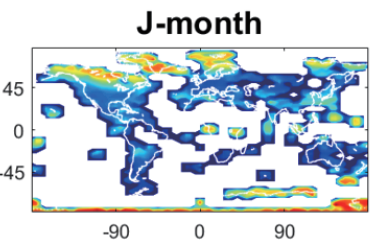
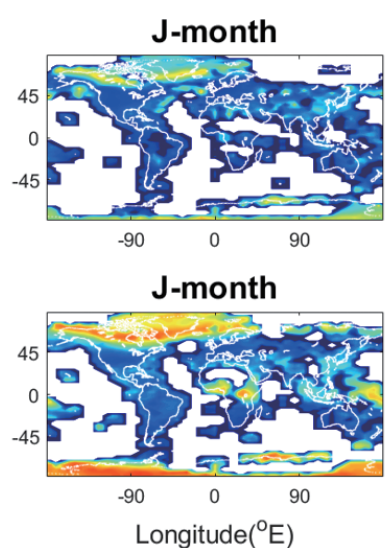

S-month

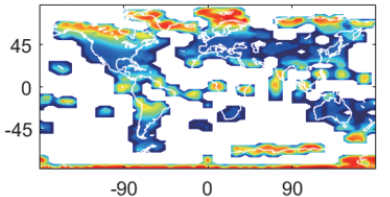

S-month

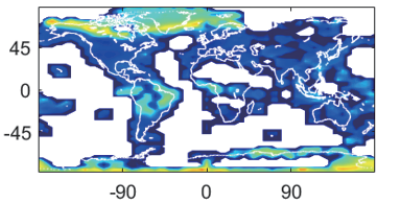

S-month

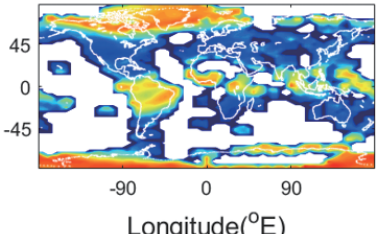

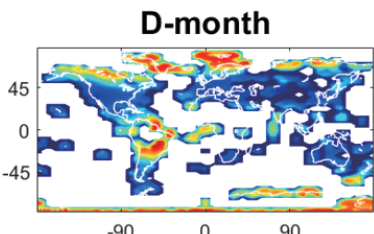

ROTI

0.5

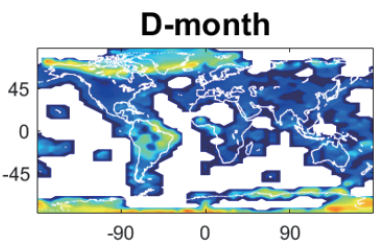

$-0.1$

0.05

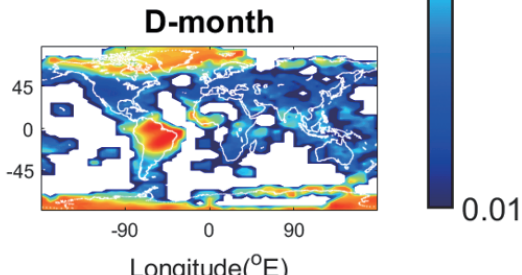

Fig. 3. Global ROTI distributions observed at nighttime of 20:00 - 02:00 LT in various months of 2000, 2009, and 2013. The median of ROTIs in the latitude $\times$ longitude window of 2.5 $\times 5$-deg during 20:00 to 02:00 LT within \pm 45 days of the month is calculated and plotted. Thus, for at a window with a single receiving station, the median will be computed by more than $524160(=120 \times 6 \times 8 \times 91)$ ROTIs. Nevertheless, for multi receiving stations, any ROTIs inside the window will be taken into consideration.

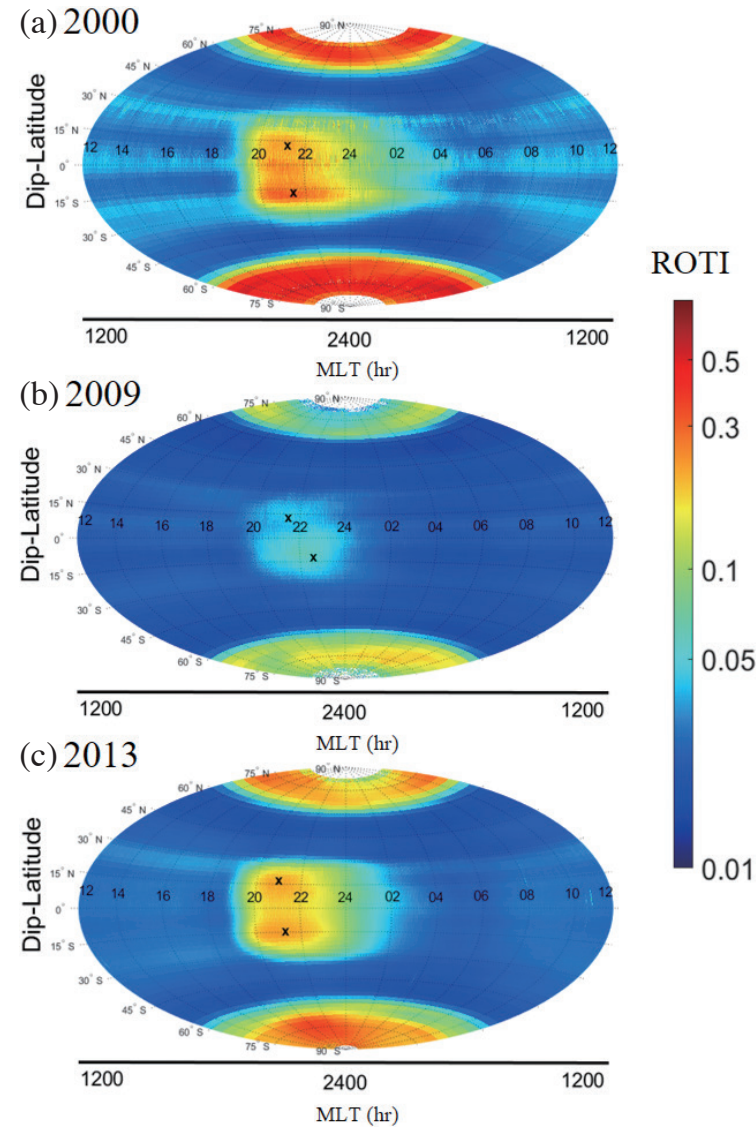

Fig. 4. Diurnal variations of ROTI in solar maximum year of 2000 (a), minimum (or super quiet) year of 2009 (b), and solar median year of 2013 (c). The black crosses represent crest peaks of ROTIs in the Northern and Southern hemisphere. The strength/latitudinal location/appearance time of crest peak of the Northern and Southern hemisphere in 2000, 2009, as well as 2013 are $0.26 / 13^{\circ} \mathrm{dip} / 2100 \mathrm{MLT}$ and $0.38 /-18^{\circ} \mathrm{dip} / 2100 \mathrm{MLT}$, $0.05 / 13^{\circ} \mathrm{dip} / 2200 \mathrm{MLT}$ and $0.06 /-13^{\circ} \mathrm{dip} / 2300 \mathrm{MLT}$, as well as $0.23 / 18^{\circ} \mathrm{dip} / 2100 \mathrm{MLT}$ and $0.23 /-15^{\circ} \mathrm{dip} / 2100 \mathrm{MLT}$, respectively. 


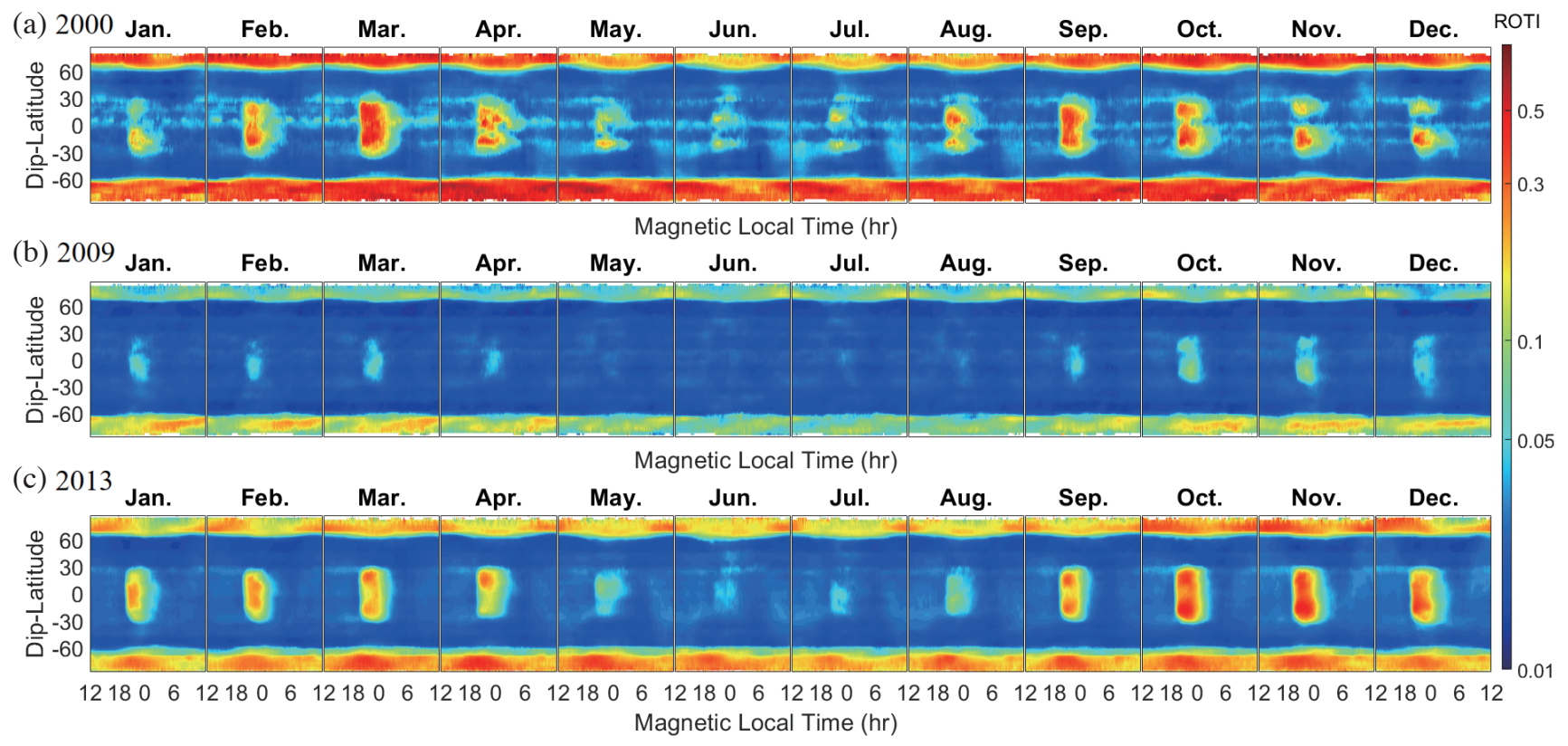

Fig. 5. Monthly variations of ROTI in (a) 2000, (b) 2009, and (c) 2013.
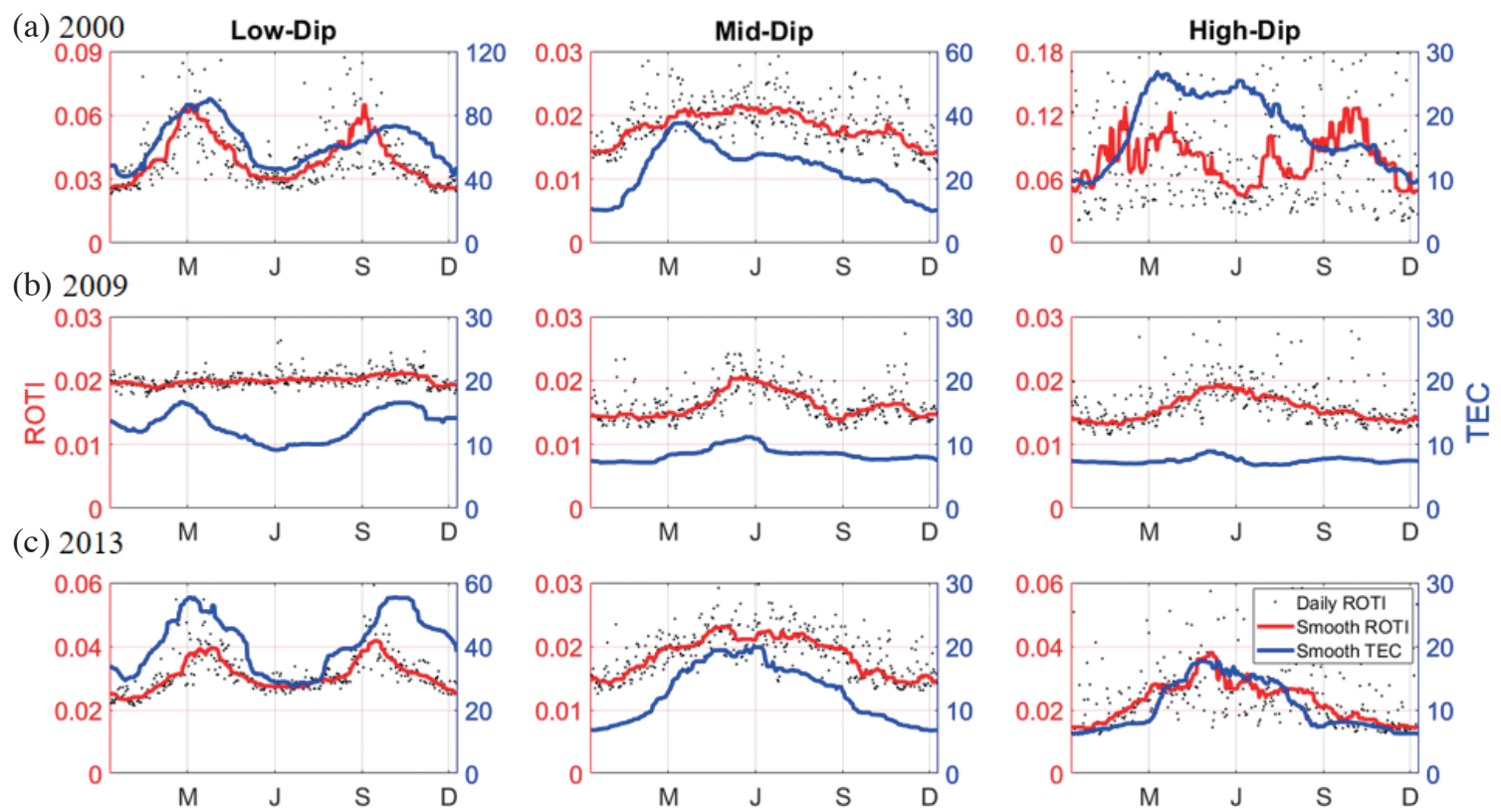

Fig. 6. The daily median of ROTI and TEC at the low-, middle-, and high-latitude in 2000, 2009, and 2013. The gray dots stand for the daily median of ROTI. The red and blue curves denote the smoothed daily ROTI and TEC calculated by a \pm 45 day moving window, respectively. 
TEC reach maximums in March to April and September to October, and the two quantities are proportional to the solar activities. Note that the monthly variation of ROTI at low latitudes in 2009 maintains a constant value of about 0.02 , which indicates no obvious seasonal variation. In the middle latitude, ROTI tends to be large values around May to June of the three years, while TEC yields the maximum in late March of 2000, and in May to June of 2009 and 2013. Although at the middle latitude, TEC in 2009 is much smaller than those in 2000 and 2013, values and trends of ROTI in 2000, 2009, and 2013 are rather similar. Thus, the middlelatitude TEC is proportional to the solar activity while the associated ROTI seems not. Nevertheless, the middle-latitude TEC yields the lowest value of the globe. In the high latitudes, ROTI yields an extremely high value and reaches maximums in late February-early April and late SeptemberOctober, while TEC has maximums in late march, June, and October in 2000. ROTI and TEC reach their maximums in May of 2009 and 2013. In general, both high latitude ROTI and TEC are evidently proportional to the solar activity.

In each year, TEC yields the greatest maximum value in the low latitude, and the smallest one in the high latitude. However, ROTI reaches the greatest value in the high latitude, the $2^{\text {nd }}$ in the low latitude, and the smallest in middle latitude in 2000. In the solar minimum (super quiet solar activity) of 2009, ROTI is near a constant value of about 0.02 in the low latitude, those in the middle and high latitudes are similar and reach the maximum value of 0.02 in late May. In the moderate solar activity of 2013, the maximum value of ROTI in the high latitude is greater than that in the middle latitude, and approaches the one in the low latitude. Nevertheless, Fig. 6 shows that ROTI is significantly proportional to the solar activity, and frequently yields very large values in the high latitudes.

To study the solar activity variations of ROTI and TEC, we further apply the box-and-whisker procedure (Wilcox 2010), which has an advantage of visually observing the significant difference among multi-datasets simultaneously. The ends of the box are the upper and lower quartiles, where the lower (upper) quartile is the number such that at least $25 \%$ of observations are less (greater) than or equal to it. The horizontal line within the box denotes the median. If two boxes do not overlap with each other, we claim that there is a dramatic difference between the two boxes. However, when one shorter box with median larger than the upper quartile or smaller than the lower quartiles of the other longer box, the two boxes are still declared to be different. Figure 7 illustrates box-and-whisker (box) plots of ROTI and TEC in the three latitudes and in three years. It can be seen in each latitude that ROTI or TEC in the three years are significantly different, which indicates that the two quantities are significantly proportional to the solar activity. TEC has the greatest value at the low latitude in each year, while ROTI yields the greatest one at high (low) latitude in
$2000(2009,2013)$, which agree well with Fig. 6. We further compute the correlation coefficient as well as the slope between ROTI and TEC in the three latitudes and the three years. Figure 8 illustrates the yearly correlation coefficient that ROTI and its ambient TEC are correlated well, except the correlation coefficient of 0.22 at the low latitude in the super quiet year of 2009 and that of 0.04 at the high latitude in the high solar activity year of 2000 . The correlation coefficient and $95 \%$ confident interval of $0.04[-0.060 .15]$ show that the relationship between ROTI and TEC is insignificant during the high solar activity year of 2000 .

Ground-based GNSS receivers observe ROTIs over the land/continental areas, while F3/C S4 sounding can uniformly cover the globe (Fig. 1). This allows us conducting an extrapolation to fill ROTI gaps over the ocean areas in the low latitudes (Fig. 3). Figures 4 and 5 show that the diurnal, monthly, and solar activity variations of ROTI are similar to those of F3/C S4 (Liu et al. 2016; Chen et al. 2017). On the other hand, Carrano et al. (2019) compare theoretical and observational results of the low latitude ionosphere over Ascension Island $\left(7.96^{\circ} \mathrm{S}, 14.41^{\circ} \mathrm{W}\right.$, dip latitude $\left.12.4^{\circ} \mathrm{S}\right)$ and find that co-located ROTI and S4 are highly correlated. Based on the above studies, it is possible to predict the annual variation of the low latitude ROTI at various longitudes in some more detail, if the relationship between ROTI and F3/C S4 is computed. Figure 9 shows at the low latitude that the correlations between ROTI and F3/C S4 index computed from an empirical model (Chen et al. 2017) all fall in the $95 \%$ confident interval in the three years, and they are relatively high in 2000 and 2013. The detailed studies reveal that the monthly correlations between ROTI and S4 are significant, except May to August in 2009. Figure 10 illustrates the low latitude ROTI in months versus longitudes. Due to no ground-based GNSS receiver available, there are several data gaps in ROTIs (Figs. 10a - c). Based on the slope of the fitted graph in Fig. 9, we convert the S4 values to ROTI values and then combine the existing ROTI datasets in Figs. $10 \mathrm{a}$ - $\mathrm{c}$ to obtain the low-latitude ROTI in months versus longitudes of the globe in each year. Figures $10 \mathrm{~d}$ and $\mathrm{f}$ show that prominent ROTIs appear -70 to $-15^{\circ} \mathrm{E}$ in January, expand to a wide range of -135 to $180^{\circ} \mathrm{E}$ in March to April, however become very weak (almost ROTI free) at two longitude sectors of -110 to $-10^{\circ} \mathrm{E}$ and 45 to $140^{\circ} \mathrm{E}$ during May to September, again cover the whole longitude in October, and finally shrink down -100 to $5^{\circ} \mathrm{E}$ and scatter around 90 to $140^{\circ} \mathrm{E}$ in December. Thus, the low-latitude ROTI of months versus longitudes looks like a masquerade mask with two eye holes of ROTI free at two longitude sectors of -100 to $-10^{\circ} \mathrm{E}$ and 45 to $140^{\circ} \mathrm{E}$ during May to September. In fact, similar masquerade mask features can be found in contour plot representing EPB (equatorial plasma bubble) rates on a month versus longitude grid (Gentile et al. 2006) and in the longitude-month distribution of the maximum S4 index (Huang et al. 2014). 

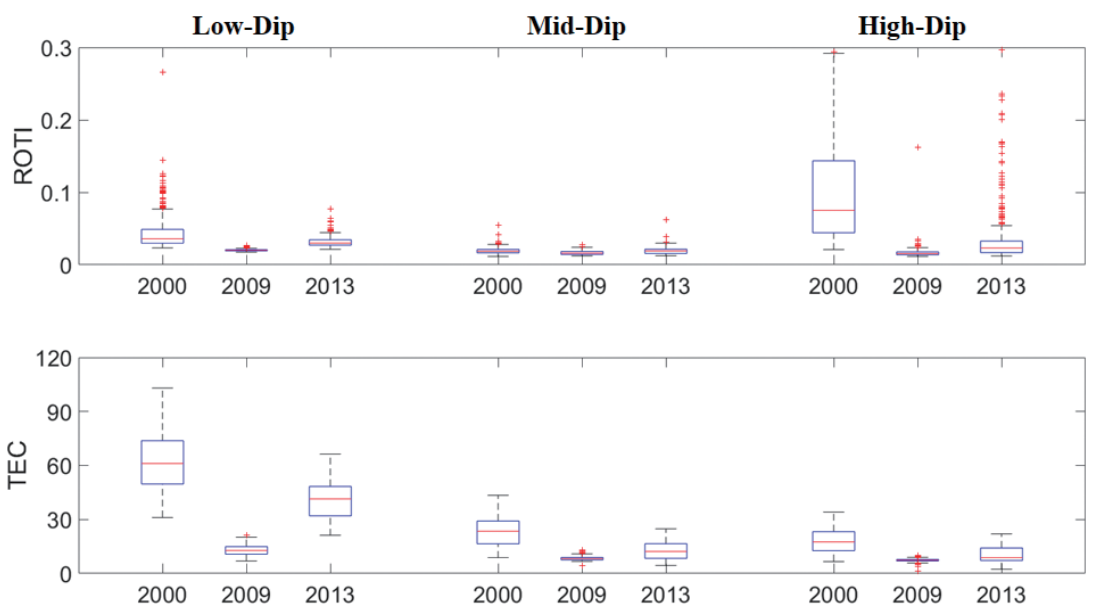

Fig. 7. Boxplots of ROTI and TEC at each dip latitude zone in 2000, 2009, and 2013.

(a)

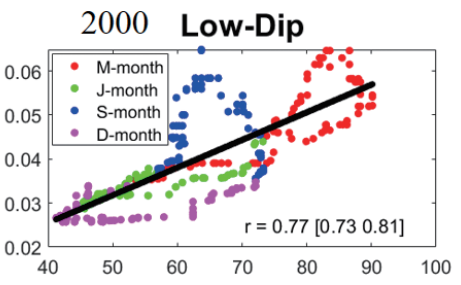

(b)

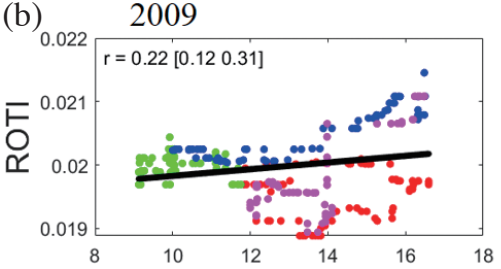

(c)

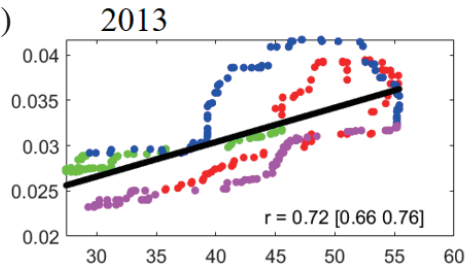

Mid-Dip
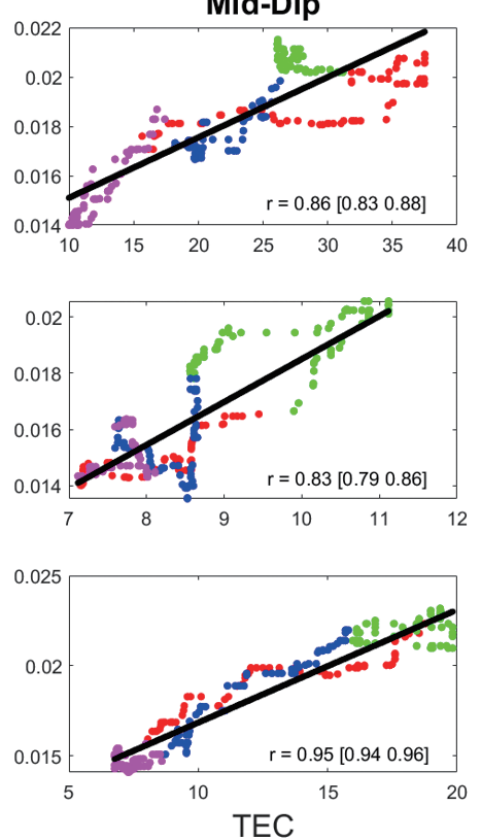
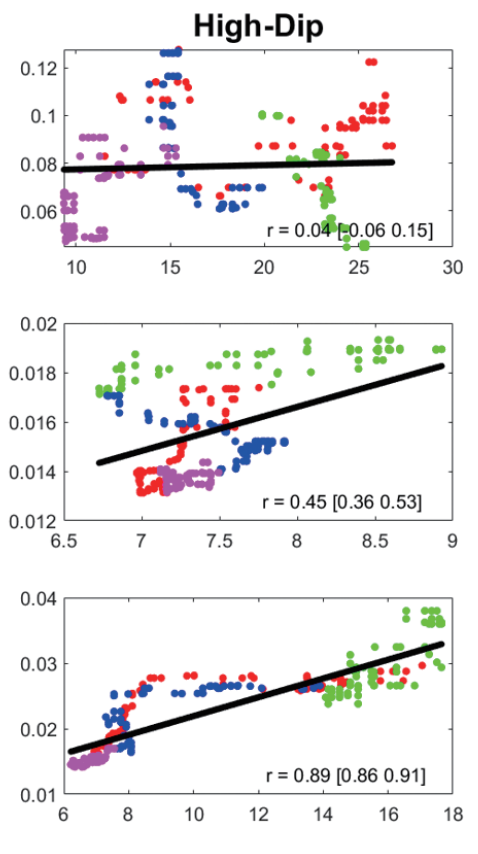

Fig. 8. Scatter plots for ROTI versus TEC at each dip latitude zone in 2000, 2009, and 2013. The black lines in each panel stand for the linear fitting of ROTI and TEC. Red, green, blue, and magenta dots denote data in M-, J-, S-, and D-month, respectively. 
(a) 2000

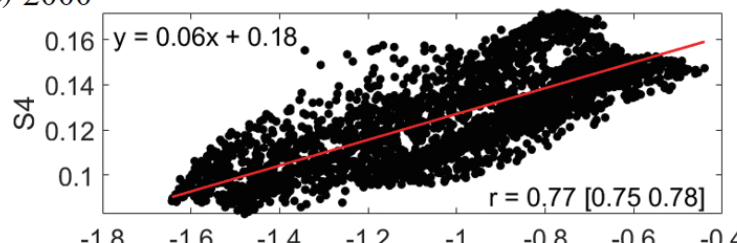

(b) 2009

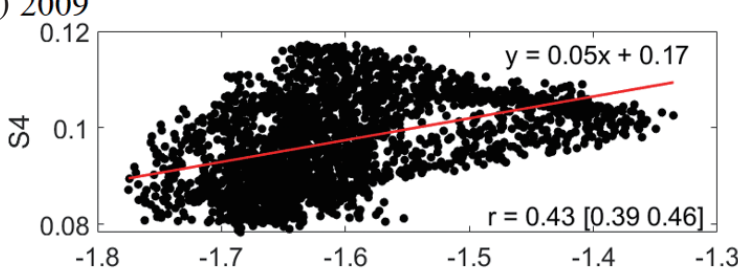

(c) 2013

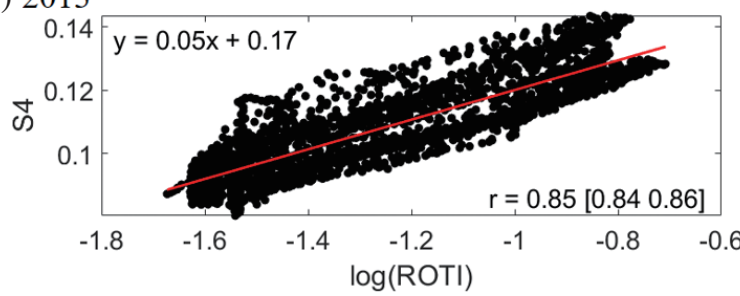

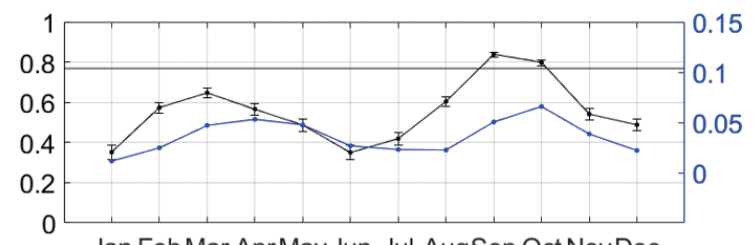

Jan Feb Mar Apr May Jun Jul AugSep Oct NovDec

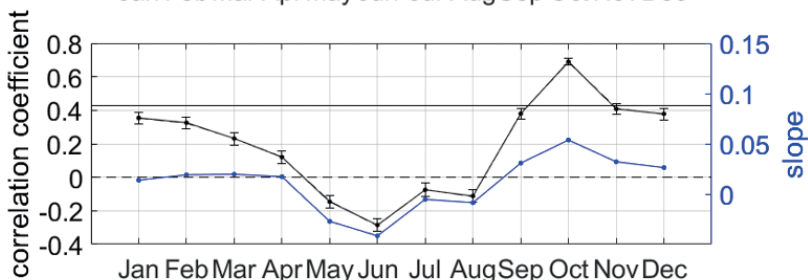

Jan Feb Mar Apr May Jun Jul AugSep Oct NovDec

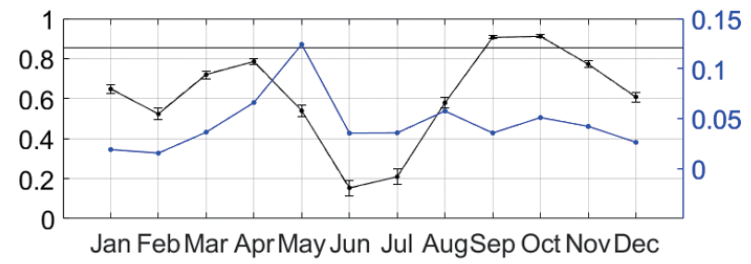

Fig. 9. Scatter plots (left panels) and correlation coefficient/slope (right panels) of S4 versus $\log _{10}$ (ROTI) at the low latitude in 2000,2009 , and 2013. Red lines stand for the linear fitting of $\log _{10}(\mathrm{ROTI})$ and $\mathrm{S} 4$. The black line is the correlation coefficient of each year. Black and blue segments denote the correlation coefficient and slope, respectively.

(a) 2000

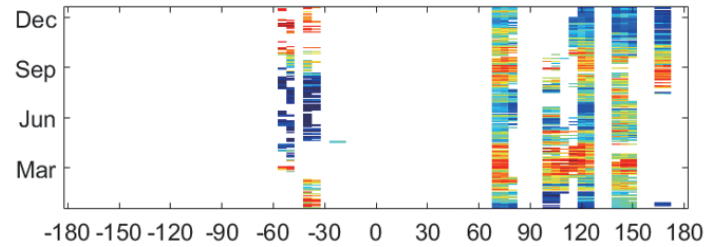

(b) 2009

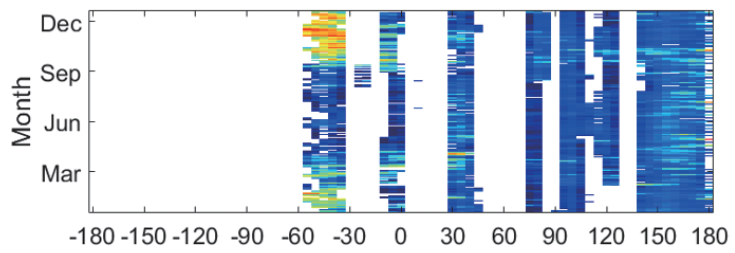

(c) 2013

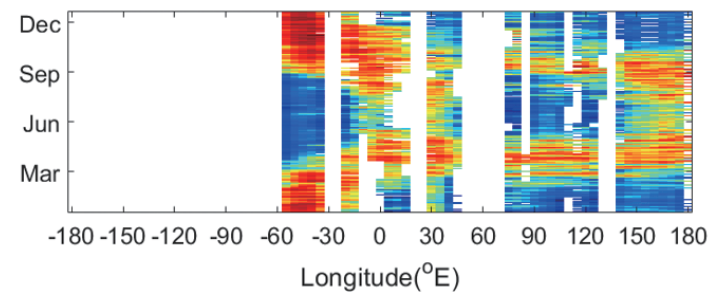

(d) 2000

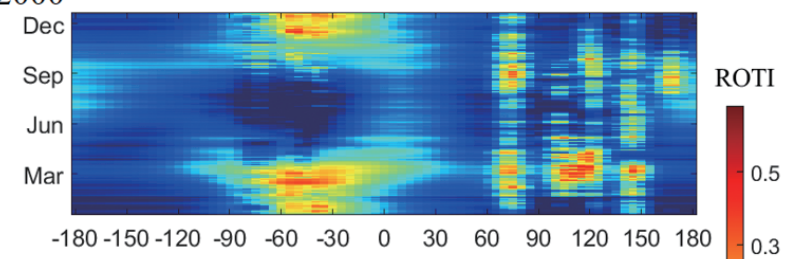

(e) 2009

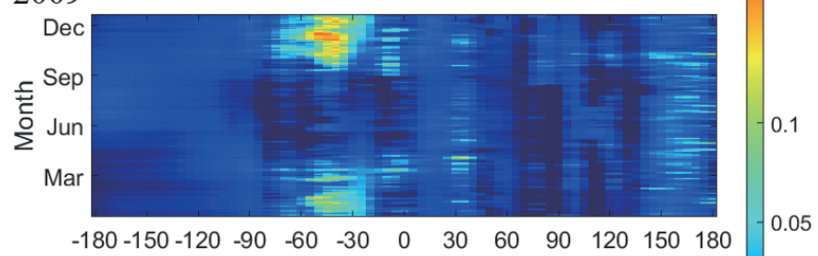

(f) 2013

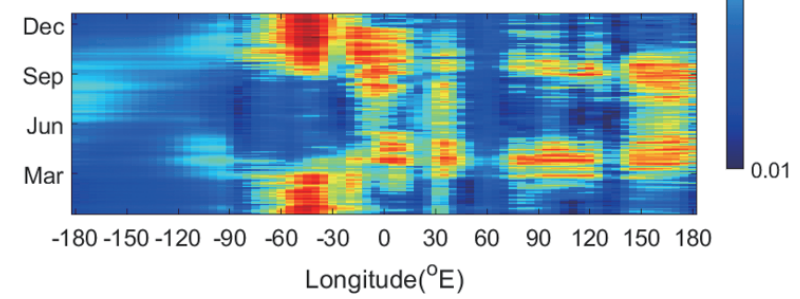

Fig. 10. The month-longitude-ROTI plots in 2000, 2009, and 2013. (a) - (c) ROTI observations, and (d) - (f) ROTI observations plus F3/C S4 model extrapolations in each year. 


\section{DISCUSSION AND CONCLUSION}

Recently, signals of high sample rate of $50 \mathrm{~Hz}$ GNSS sounded on the ground (cf. Jin and Oksavik 2018) have been used study amplitude and phase scintillations caused by plasma irregularities embedded in the ionosphere. However, GNSS receivers with such a high sample rate often yields relatively limited coverage. In contrast, ROTI (Pi et al. 1997 ) with the low sample rate of 30 -sce can be employed to examine the irregular structure of TEC temporal changes and spatial gradients of the globe ionosphere (Fig. 1). Liu et al. (2004) show that the Doppler shift $\Delta f$ is made up of two parts: a part due to the motion of the satellite with respect to the receiver, and a part due to the rate of change of the total electron content $d T E C / d t$ along the path, which can be expressed as,

$\Delta f=f \mu_{s} \frac{v_{l}}{c}+\frac{d \mathrm{TEC}}{d t} \approx \frac{40.3}{c f} \frac{\Delta \mathrm{TEC}}{\Delta t}$

where $m_{s}$ is the refractive index around the satellite's environment, $v_{l}$ is the line-of-sight component of the GNSS satellite velocity, $c$ is the light speed in free space, and $f$ denotes for the GNSS carrier phase. With a relatively slow and constant speed of the GNSS satellite, the first term in Eq. (2) is about a small constant and a Doppler shift is mainly caused by temporal changes in TEC (i.e., ROT). Therefore, phase changes of the GNSS signal $(\Delta \phi)$ can be given as,

$\Delta \phi=\frac{2 \pi \times 40.3}{c f} \mathrm{ROT}$

Thus, based on Eqs. (1) and (3), ROTI is a standard deviation of phase changes in the GNSS signal. In the nighttime, the mean horizontal plasma drift is about $125 \mathrm{~m} \mathrm{~s}^{-1}$ eastward at the low latitude, while that is about $25 \mathrm{~m} \mathrm{~s}^{-1}$ poleward and/or eastward at the high latitude (Kelley 2009). The time resolution of 1 minute of ROT and the time interval of 5 minutes time of ROTI allow us observing ionospheric plasma irregularities with the zonal (or horizontal) scale of $7.5-37.5 \mathrm{~km}$ in the low-latitude ionosphere and 1.5 $-7.5 \mathrm{~km}$ in the high latitude.

Figure 2 reveals that TEC fluctuations and ROTIs at the areq receiving station become prominent during 19:20 LT-postmidnight of 0200 MLT on 23 September 2013, which agrees well with the appearance time of S4 index recorded by a low latitude network of the SCINDA (Chen et al. 2017) and that of prominent echo powers in rangetime-time intensity sounded of an incoherent scatter radar at Jicamarca Radio Observatory (11 ${ }^{\circ} 57^{\prime} 05^{\prime}$ 'S 76 52 '28”W) (Kelley 2009). The Jicamarca radar and the S4 index are observing plasma bubbles at different scales, meters and 100s meters, respectively. These agreements indicate that for the low latitude ROTIs, equatorial F-region plasma instabilities and/or bubbles in nighttime play an important role.

For longitudinal distributions, Liu et al. (2016) report that F3/C S4 at low latitudes is much stronger than that at high latitudes and proportional to the solar activity. They find in the low-latitude ionosphere that pronounced F3/C S4 generally follow the magnetic equator in the four seasons, taking place at South American-Atlantic sector in D-month, African and Pacific sector in J-month, and around South American-Atlantic-African sector in M- and S-month. In the low-latitude ionosphere, Fig. 3 shows in general, prominent signatures in longitudes and months of F3/C S4 are similar to those of ROTIs, except that ROTIs do not experience prominent plasma irregularities over African and $\mathrm{Pa}$ cific sector in J-month. Oppositely, ROTIs at high latitudes are much stronger than those at low latitudes.

For diurnal variations, Liu et al. (2016) find that the low-latitude $\mathrm{F} 3 / \mathrm{C} \mathrm{S} 4$ situates at $\pm 25^{\circ} \mathrm{dLat}$, starting from 2000 MLT, reaching their maximum intensity at 2100 MLT, and diminishing by about 0200 MLT. The Northern F3/C $\mathrm{S} 4$ peak is stronger that the Southern one. Although it is rather weak, the polar-latitude F3/C S4 becomes prominent at $\pm 60^{\circ} \mathrm{dLat}$ and develop more strongly toward the magnetic poles but yet with no obvious diurnal variations. Figure 4 shows that the Southern ROTI crest is stronger that the Northern one in low latitudes, while ROTI in high latitudes is much stronger than that in low latitudes. Moreover, unlike F3/C S4 index of Liu et al. (2016), but similar to geostationary satellite VHF signals of Basu et al. (1988), ROTIs yield very intense belts observed at high latitudes. Again, ROTIs at the high latitude are much stronger than those at the low latitude, which is opposite to the F3/C S4. The low latitude ROTI crest in the Southern hemisphere is stronger that in the Northern one, while the high latitude ROTI is much stronger than the low latitude one, which are opposite to the S4 index. This suggests the causal mechanisms of ROTIs and the $\mathrm{S} 4$ index being very different.

Monthly variations of ROTI in Fig. 5 are similar to F3/C S4 index in the F-region (Liu et al. 2016). At the low latitudes, ROTI and F3/C S4 index yield prominent features, which might result from stronger $\mathbf{E} \times \mathbf{B}$ plasma fountain during the prereversal enhancement around the sunset period in March and September to October (Kelley 2009). At the high latitudes, ROTI seems more evident than F3/C S4 index, and both in the Southern hemisphere are more prominent than those in the Northern hemisphere. This implies that the plasma irregularity in the Southern hemisphere is more prominent than that in the in the Northern hemisphere.

Previous studies (cf. Davies 1990) and Figs. 6 and 7 show that the electron density and TEC yield the greatest value in the low-latitude ionosphere. Olwendo et al. (2018) carried out validation of ROTI for ionospheric amplitude scintillation measurements in a low-latitude region over Africa, while Xu et al. (2019) examined statistical features of 
TEC and ionospheric scintillation over the low latitude of China. They suggest that that ROTI is greater at high latitude as the GNSS phase is easier to be affected by rapid variations of the plasma density, while the equatorial plasma irregularities including plasma bubbles affect the amplitude scintillation of GNSS. Liu et al. (2016) report that the most intense F3/C S4 index occurs in the low latitudes, and however Figs. 3 - 5 show that the strongest ROTI appears in the high latitudes. This discrepancy might result from that F3/C S4 index and ROTI stand for amplitude and phase fluctuations of GNSS signals, respectively. Meanwhile, for HF ionosonde soundings, the range and frequency spread $\mathrm{F}$ in ionograms frequently occur in the low and high latitudes, respectively (Davies 1990), which indicates that irregularities of plasma (or electron) density at the two latitudes are very different. Numerous observations of radars, airglow imagers, rockets, and satellites show that owing to the RayleighTaylor instability, ionospheric plasma irregularities are related to plasma bubbles or depletions in the low-latitude ionosphere (cf. Davies 1990; Kelley 2009). By contrast, patches and blobs of dense plasma densities could result in multi plasma frequencies at the same altitude frequency and spread F in the high latitude. Thus, we conjecture that highlatitude plasma irregularities might be frequently associated with plasma patches and blobs, which are mainly due to constantly being bombed by precipitation charged particles from the upper ionosphere or the magnetosphere.

Figure 8 reveals that ROTIs generally are proportional to their ambient TECs, except those at the low latitude in the super quiet year of 2009 and at the high latitude in the high solar activity year of 2000. Therefore, it might require a certain level of the ambient TEC to modulate the phase of GNSS signals in the low latitude. In contrast, it might be owing to intense external disturbances, such as precipitation charged particles etc., being very intense, which significantly modifies the phase of GNSS signals in the high latitude, regretless the magnitude of the ambient TEC. Nevertheless, TEC and ROTI in Figs. 3 - 8 yield prominent solar activity effects.

Since longitudinal, diurnal, and monthly variations of ROTI in Figs. 3 - 5 and those of F3/C S4 (Liu et al. 2016) yield very similar patterns and tendencies as well as Carrano et al. (2019) find that the low latitude ROTI and S4 are highly correlated, which allow us conducting extrapolations to fill ROTI data gaps over the ocean area in the low latitude. Figure 9 shows that the overall and monthly correlations between ROTI and $\mathrm{F} 3 / \mathrm{C} \mathrm{S} 4$ with $\pm 15^{\circ} \mathrm{dLat}$. Based on Fig. 9, month-longitude-ROTI plots in 2000, 2009, and 2013 are constructed. Figure 10 displays that prominent ROTIs reveal a pattern of the masquerade mask, which is like the occurrence probability and amplitude of equatorial ionospheric irregularities associated with plasma bubbles probed by the C/NOFS (Communication/Navigation Outage Forecasting System) satellite and F3/C S4 index in the low latitude during low and moderate solar activities of 2008 - 2012 (Huang et al. 2014) and contour plot of EPB rates on a month versus longitude grid (Gentile et al. 2006). Similar masquerade mask features show that ROTIs can be employed to observe monthly and longitudinal variations of ROTIs in the equatorial and low latitude ionosphere.

It can be seen that ROTIs in Figs. 3 - 10 are much smaller than those in Fig. 2. Note that in Fig. 2, ROTI is an instant one, which is calculated with ROT of 1 GPS satellite to 1 receiving station within a 5-minute window, and however in the rest figures, the median is computed by ROTIs in the latitude $\times$ longitude window of $2.5 \times 5$-deg during 20:00 to 02:00 LT (Figs. 5 and 6) together with within \pm 45 days (Figs. 3, 4, and 10) and in the 60-deg latitudinal range of the low (within $\left.\pm 30^{\circ}\right)$, middle $\left(30-60^{\circ}\right)$, and high $\left(60-90^{\circ}\right)$ dip-latitude (Figs. 7 - 9). A large amount of ROTIs results in the median being a small value. The more ROTI data, the smaller median. Nevertheless, the median derived from the large amount data shall allow us robustly and correctly find response of ROTI to the diurnal, seasonal, solar activity and latitudinal/longitudinal effects.

The detailed comparison suggests that the $\mathrm{S} 4$ index and ROTIs are sensitive to ionospheric irregularities of plasma bubbles and blobs, respectively. ROTIs caused by plasma bubbles/depletions appear in the low latitude of $\pm 30^{\circ}$ magnetic dip; start at 20:00 LT, and vanish by about 02:00 LT. The two ROTI crests become prominent and move poleward in the spring and autumn equinox months, which indicate that the $\mathbf{E} \times \mathbf{B}$ plasma fountain of the prereversal enhancement and the Rayleigh-Taylor instability are essential to yield prominent ROTIs in the low latitude ionosphere. The low-latitude ROTI crest in the Southern hemisphere is more intense than that in the Northern one. At the high latitudes, precipitation charged particles from the magnetosphere can frequently produce promonent plasma patches and blobs in the ionosphere. ROTIs at the high latitudes are much more intense than those at the low latitudes, which suggests ROTI is more sensitive to irregularities of plasma patches or blobs than plasma bubbles or depletions. Antarctic ROTIs are stronger than Arctic ones in all seasons, which indicates that plasma irregularities are more prominent in the southern polar region than those in the northern one. In conclusion, measurements of the existing IGS receiving stations provide us a good opportunity to globally monitor and study ionospheric plasma irregularities in various local times, seasons, and solar activities.

Acknowledgements Measurements of worldwide groundbased GNSS receivers with the 30 -sec time resolution can be retrieved from IGS (International GNSS services, http:// garner.ucsd.edu/). This study is supported by the Taiwan Ministry of Science and Technology grant MOST 1082119-M-008-001. This work was financially supported by the Center for Astronautical Physics and Engineering 
(CAPE) from the Featured Area Research Center program within the framework of Higher Education Sprout Project by the Ministry of Education (MOE) in Taiwan.

\section{REFERENCES}

Basu, S., E. MacKenzie, and S. Basu, 1988: Ionospheric constraints on VHF/UHF communications links during solar maximum and minimum periods. Radio Sci., 23, 363-378, doi: 10.1029/rs023i003p00363. [Link]

Berkner, L. V. and H. W. Wells, 1934: $F$-region ionosphereinvestigations at low latitudes. Terr. Magn. Atmos. Electr., 39, 215-230, doi: 10.1029/TE039i003p00215. [Link]

Carrano, C. S., K. M. Groves, and C. L. Rino, 2019: On the relationship between the rate of change of total electron content index (ROTI), irregularity strength $\left(C_{k} L\right)$, and the scintillation index $\left(S_{4}\right)$.J. Geophys. Res., 124, 2099-2112, doi: 10.1029/2018JA026353. [Link]

Chen, S.-P., D. Bilitza, J.-Y. Liu, R. Caton, L. C. Chang, and W.-H. Yeh, 2017: An empirical model of L-band scintillation S4 index constructed by using FORMOSAT-3/COSMIC data. Adv. Space Res., 60, 10151028, doi: 10.1016/j.asr.2017.05.031. [Link]

Cherniak, I. and I. Zakharenkova, 2016: First observations of super plasma bubbles in Europe. Geophys. Res. Lett., 43, 11137-11145, doi: 10.1002/2016GL071421. [Link]

Cherniak, I., I. Zakharenkova, and R. J. Redmon, 2015: Dynamics of the high-latitude ionospheric irregularities during the 17 March 2015 St. Patrick's Day storm: Ground-based GPS measurements. Space Weather, 13, 585-597, doi: 10.1002/2015SW001237. [Link]

Cherniak, I., A. Krankowski, and I. Zakharenkova, 2018: ROTI Maps: A new IGS ionospheric product characterizing the ionospheric irregularities occurrence. GPS Solut., 22, doi: 10.1007/s10291-018-0730-1. [Link]

Clausen, L. B. N., J. I. Moen, K. Hosokawa, and J. M. Holmes, 2016: GPS scintillations in the high latitudes during periods of dayside and nightside reconnection. J. Geophys. Res., 121, 3293-3309, doi: 10.1002/2015JA022199. [Link]

Davies, K., 1990: Ionospheric Radio, Peter Peregrinus Ltd., London, U.K., 580 pp.

Gentile, L. C., W. J. Burke, and F. J. Rich, 2006: A global climatology for equatorial plasma bubbles in the topside ionosphere. Ann. Geophys., 24, 163-172, doi: 10.5194/angeo-24-163-2006. [Link]

Huang, C.-S., O. de La Beaujardiere, P. A. Roddy, D. E. Hunton, J. Y. Liu, and S. P. Chen, 2014: Occurrence probability and amplitude of equatorial ionospheric irregularities associated with plasma bubbles during low and moderate solar activities (2008-2012). J. Geophys. Res., 119, 1186-1199, doi: 10.1002/2013JA019212.
[Link]

Jacobsen, K. S., 2014: The impact of different sampling rates and calculation time intervals on ROTI values. J. Space Weather Space Clim., 4, A33, doi: 10.1051/ swsc/2014031. [Link]

Jacobsen, K. S. and S. Schäfer, 2012: Observed effects of a geomagnetic storm on an RTK positioning network at high latitudes. J. Space Weather Space Clim., 2, A13, doi: 10.1051/swsc/2012013. [Link]

Jin, Y. and K. Oksavik, 2018: GPS scintillations and losses of signal lock at high latitudes during the 2015 St. Patrick's Day storm. J. Geophys. Res., 123, 7943-7957, doi: 10.1029/2018JA025933. [Link]

Jin, Y., J. I. Moen, and W. J. Miloch, 2014: GPS scintillation effects associated with polar cap patches and substorm auroral activity: Direct comparison. J. Space Weather Space Clim., 4, A23, doi: 10.1051/swsc/2014019. [Link]

Jin, Y., J. I. Moen, K. Oksavik, A. Spicher, L. B. N. Clausen, and W. J. Miloch, 2017: GPS scintillations associated with cusp dynamics and polar cap patches. J. Space Weather Space Clim., 7, A23, doi: 10.1051/ swsc/2017022. [Link]

Kelley, M. C., 2009: The Earth's Ionosphere: Plasma Physics and Electrodynamics, 2nd Ed., Academic Press, $556 \mathrm{pp}$.

Kotulak, K., I. Zakharenkova, A. Krankowski, I. Cherniak, N. Wang, and A. Fron, 2020: Climatology characteristics of ionospheric irregularities described with GNSS ROTI. Remote Sens., 12, 2634, doi: 10.3390/ rs12162634. [Link]

Krankowski, A., I. I. Shagimuratov, L. W. Baran, I. I. Ephishov, and N. J. Tepenitzyna, 2006: The occurrence of polar cap patches in TEC fluctuations detected using GPS measurements in southern hemisphere. Adv. Space Res., 38, 2601-2609, doi: 10.1016/j. asr.2005.12.006. [Link]

Liu, J. Y., H. F. Tsai, and T. K. Jung, 1996: Total electron content obtained by using the global positioning system. Terr. Atmos. Ocean. Sci., 7, 107-117, doi: 10.3319/TAO.1996.7.1.107(A). [Link]

Liu, J. Y., C. H. Lin, H. F. Tsai, and Y. A. Liou, 2004: Ionospheric solar flare effects monitored by the groundbased GPS receivers: Theory and observation. J. Geophys. Res., 109, A01307, doi: 10.1029/2003JA009931. [Link]

Liu, J. Y., S. P. Chen, W. H. Yeh, H. F. Tsai, and P. K. Rajesh, 2016: Worst-case GPS scintillations on the ground estimated from radio occultation observations of FORMOSAT-3/COSMIC during 2007-2014. Surv. Geophys., 37, 791-809, doi: 10.1007/s10712-0159355-x. [Link]

Moen, J., K. Oksavik, L. Alfonsi, Y. Daabakk, V. Romano, and L. Spogli, 2013: Space weather challenges of the 
polar cap ionosphere. J. Space Weather Space Clim., 3, A02, doi: 10.1051/swsc/2013025. [Link]

Olwendo, J. O., P. Cilliers, Z. Weimin, O. Ming, and X. $\mathrm{Yu}, 2018$ : Validation of ROTI for ionospheric amplitude scintillation measurements in a low-latitude region over Africa. Radio Sci., 53, 876-887, doi: 10.1029/2017RS006391 [Link]

Pi, X., A. J. Mannucci, U. J. Lindqwister, and C. M. Ho, 1997: Monitoring of global ionospheric irregularities using the worldwide GPS network. Geophys. Res. Lett., 24, 2283-2286, doi: 10.1029/97gl02273. [Link]

Su, S.-Y., C. H. Liu, H. H. Ho, and C. K. Chao, 2006: Distribution characteristics of topside ionospheric density irregularities: Equatorial versus midlatitude regions. J. Geophys. Res., 111, A06305, doi: 10.1029/2005JA011330. [Link]

Van der Meeren, C., K. Oksavik, D. A. Lorentzen, M. T. Rietveld, and L. B. N. Clausen, 2015: Severe and lo- calized GNSS scintillation at the poleward edge of the nightside auroral oval during intense substorm aurora. J. Geophys. Res., 120, 10607-10621, doi: 10.1002/2015JA021819. [Link]

Wang, J. and Y. T. Morton, 2017: A comparative study of ionospheric irregularity drift velocity derived from a GNSS receiver array and Poker Flat Incoherent Scatter Radar measurements during high-latitude ionospheric scintillation. J. Geophys. Res., 122, 6858-6881, doi: 10.1002/2017JA024015. [Link]

Wilcox, R. R., 2010: Fundamentals of Modern Statistical Methods: Substantially Improving Power and Accuracy, Springer-Verlag New York, New York, USA, 249 pp, doi: 10.1007/978-1-4419-5525-8. [Link]

$\mathrm{Xu}$, L., J. Cheng, and J. S. Xu, 2019: Statistical features of TEC and ionospheric scintillation over the low latitude of China. Adv. Space Res., 64, 2164-2175, doi: 10.1016/j.asr.2019.07.011. [Link] 